\title{
Whewell on the Classification of the Sciences
}

\begin{abstract}
Despite deserving a place amongst the historic milestones of the philosophy of disciplines, the system of the sciences put forward by Whewell has so far received little interest. Yet his ideas had a significant impact on the researches subsequently carried out on the topic, exerting in particular a decisive influence on Peirce and Spencer. The present paper aims to display the innovatory nature of the philosophical foundations of the Whewellian classification of the sciences. In this respect, we will argue that the most striking feature of his disciplinary system lies in a heuristic categorization of the sciences according to their "methods of discovery". This represents a double departure from both the Aristotelian and the Baconian disciplinary paradigms, which are instead underpinned by ontological and epistemological criteria, respectively. Next, we will explore the pivotal role of Whewell's classification of the sciences for his overall project of a philosophy of scientific discovery.
\end{abstract}

Keywords: William Whewell $\cdot$ history of disciplines $\cdot$ classification of the sciences $\cdot$ interdisciplinarity · unity of science 


\section{INTRODUCTION}

Thanks to the fundamental work of Fisch $(1985,1991)$ and Yeo $(1979,1993)$, along with a renewed interest in William Whewell in recent years (see, for instance, Wettersten 2005; Snyder 2006; Cobb 2011 ; Wilson 2011), the significance of Whewell's contributions to the philosophy of science is now widely recognized. However, little study has been so far devoted to his classification of scientific disciplines, aside from brief mentions in some treatises intended to cover the history of disciplines in a comprehensive manner (e.g., Flint 1904). Yet, this classification is a theme of major importance for understanding the Whewellian philosophical ideas about the structure of science. Indeed, a glance at the contents of his Philosophy of Inductive Sciences (1840) reveals a structure moulded by the principles given in the classificatory table of scientific disciplines included in the treatise (Book XI). Furthermore, the philosophy of classification in general appears to be a central topic for Whewell, who expended much energy identifying a coherent system for classifying minerals (Whewell 1828). In the present paper, we will analyse the foundations of his organization of science into subfields, and its place and significance in the history of disciplines.

A striking characteristic of the Whewellian disciplinary system lies in its heuristic ${ }^{1}$ design: "the Classification of Sciences has its chief use in pointing out to us the extent of our powers of arriving at truth" (Whewell 1840, XI.IX.1). In other words, he "held the view that science could be divided naturally into several distinct areas, according to the different topics and methods practised" (Cantor 1991, 72). Such a purpose fits into the scheme of the overall Whewellian attempt to "analyse and methodize the process of discovery" (Yeo 1993, 165). In his Philosophy of Inductive Sciences, Whewell undertakes an analysis of the various "methods employed in the formation of science", with the stated objective of "resolving the Process of Discovery into its parts, and to give an account as distinct as may be of Rules and Methods which belong to each portion of the process" (Whewell 1840, XIII.I). The structure of the disciplinary scheme developed by Whewell is based on a list of "fundamental principles I shall afterwards proceed to discuss and to exhibit in each of the principal departments of science" (ibid., I.VI.2). It is important to note that such a methodological focus must not be confused with the pursuit of practical purposes. In this respect, Whewell emphasized very clearly that "Practical Arts [...] are not Sciences. And it is only by this rigorous separation of the Practical from the Theoretical, that we can arrive at any solid conclusions respecting the nature of truth, and the mode of arriving at it" (ibid., XI.VIII).

Three main disciplinary "paradigms" can be identified amongst the numerous historical attempts to compartmentalize science into subfields. A first approach consists in distinguishing the sciences according to the objects investigated by each of them. The archetype of such an ontological system is portrayed in the Aristotelian classification of the sciences, relying on a system of genera, species, and differentia, aimed at grouping natural things into categories. Another possible means of setting

Whewell appears to have been a pioneer, with Coleridge, in introducing the word "heuristic" in the sense of "serving to discover", which is still in use nowadays (Oxford English Dictionary): "If you will not let me treat the Art of Discovery as a kind of Logic, I must take a new name for it, Heuristic, for example" (Whewell 1860, Todhunter's ed. 1876, II.418). 
up a disciplinary structure can be found in the Baconian division of human knowledge according to the faculties of the mind. Prevailing during the seventeenth and the eighteenth centuries (Totok 1980, Klein 2003), such an epistemological model was still extremely influential in Whewell's time (Wettersten 1994, 717). Last but not least, a third approach to organizing the sciences - that propounded by Whewell - is delineating scientific subfields according to the methods of discovery ${ }^{2}$ implemented by each of them. A clear and explicit distinction between these three disciplinary paradigms for organizing the structure of science is drawn by several nineteenth-century scholars, most particularly Ampère, who states in his Exposition analytique d'une classification naturelle de toutes les connaissances humaines:

Autre chose est de classer les objets de nos connaissances, autre chose de classer nos connaissances elles-mêmes ; autre chose, enfin, de classer les facultés par lesquelles nous les acquérons. Dans le premier cas, on ne doit avoir égard qu'aux caractères qui dépendent de la nature des objets; dans le second, il faut combiner ces caractères avec ceux qui tiennent à la nature de notre intelligence ; dans le troisième, [...] il faut tenir compte des opérations intellectuelles qu'exige l'étude des objets dont on s'occupe. (Ampère 1834, $\mathrm{xx}-\mathrm{xxi}$ )

A similar tripartition is evidenced in various aspects of Whewell's work. In Appendix C of the Philosophy of Discovery (1860), in particular, he expounds the Platonician philosophy by means of a meaningful tabular reading grid, whose headings in the first column-object, faculties, and processes - echo a recognition of three such classificatory levels. In this respect, the Whewellian system of the sciences is explicitly positioned at the heuristic level, in marked contrast to the other two disciplinary frameworks (ontological and epistemological), which are rejected. Indeed, while acknowledging his debt to both Aristotelian and Baconian traditions, Whewell highlights the limits of the disciplinary paradigms put forth by his eminent predecessors. On the one hand, he reproaches the Aristotelian model to be too ontological, focused on the objects and facts investigated by each science: "Aristotle made in almost every province of human knowledge a vast collection of special facts. [...] When to the facts we must add the right Inductive Idea, in order to obtain truth, we find little of value in the Aristotelic works" (ibid., XII.III). On the other hand, the Baconian system, although a major source of inspiration for Whewell (Snyder 1999), is not free of criticism and is considered too epistemological. Indeed, in trying to establish the "map of human knowledge" according to the "faculties of the rational soul", the author of the Description of the Intellectual Globe (Bacon 1612) fails to organize science according to the heuristic principles enabling the "advancement of science" he so coveted:

Bacon's survey was made for the purpose of tracing the boundaries, rather than of detecting the principles of knowledge. [...] The object of our perambulation in the first place, is not so much to determine the extent of the field, as the sources of its fertility. We would learn by what plan and rules of culture, conspiring with the native forces of the bounteous soil, those rich harvests have been produced which fill our garners. (Whewell 1840, I.I).

It is important to note that, for Whewell, methods of "discovery" can also play a role in the justification of scientific theories: "We can often reason downwards from the causes so discovered; and we are thus led to suggestions of new phenomena [...]. Such proceedings may be termed Verifications of our Doctrines by such an application of our Discoveries" (Whewell 1840, XIII.I.4). 
The criticism is even sharper against Bacon's seventeenth- and eighteenth-century followers, especially Diderot and d'Alembert who adopted in the Discours préliminaire (1751) a Baconian classification for organizing the contents of the Encyclopédie:

The classification of sciences which accompanies the Discourse [...] has for its basis the classification proposed by Bacon, in which the parts of human knowledge are arranged according to the faculties of the mind in which they originate; and these faculties are taken, both by Bacon and by Dalembert, as Memory, Reason, and Imagination. The insufficiency of Bacon's arrangement as a scientific classification is so glaring, that the adoption of it, with only superficial modifications, at the period of the En cyclopedia, is a remarkable proof of the want of original thought and real philosophy at the time of which we speak. (Whewell 1840, XII.XIV, 306)

In other terms, Whewell rejects both the ontological and the epistemological paradigms as relevant systems for organizing scientific fields. His own heuristic system is very different from the other two, proposing an innovative classification of the sciences that "depends neither upon the faculties of the mind to which the separate parts of our knowledge owe their origin, nor upon the objects which each science contemplates" (Whewell 1840, XI.IX.2).

\section{WHEWELL'S PHILOSOPHY OF CLASSIFICATION}

Before analysing Whewell's disciplinary system per se, let us first examine his broader approach to the "philosophy of classification". This topic was of major importance for him, especially given his attempts to classify minerals. The following passage from the Philosophy of Inductive Sciences testifies to the inspirational role of such research for his classification of the sciences:

We thus find some of the widest and deepest questions of the philosophy of classification brought under our consideration when we would provide a method for the classification of minerals. The answers to these questions are given by M. Necker. [...] M. Necker asserts that the distinctions of different sciences depend, not on the objects they consider, but on the different and independent points of view on which they proceed. Each science has its logic, that is, its mode of applying the general rules of human reason to its own special case. (Whewell 1840, VIII.III.8)

Therefore, it makes sense to begin our analysis of Whewell's philosophy of classification with his Essay on Mineralogical Classification and Nomenclature (1828), a treatise in which he explains how to build a relevant classification. According to his view, a classificatory system cannot rely on the expected properties of its objects: "the method which first suggests itself, is to arrange them into divisions according to some assumed mark [...]. It is found however, with respect to such methods, that they can never be carried through without violating materially those natural relationships and family resemblances among different kinds of individuals" (Whewell 1828, sect. V). Thus, it is necessary to completely change the foundations of the system: "we must adopt another and different mode of classifying. [...] It does not appear possible to fix beforehand which of such attributes shall be considered as decisive" (ibid.). To be relevant, a classification system must be established with heuristic purposes in mind. That is to say, the criteria used to categorize entities into classes should not be drawn from their postulated properties, but established on the basis of tests specifically designed for their recognition and differentiation. Instead of having to presuppose (often wrongly) the 
results of our scientific investigations through classificatory characters determined beforehand, it is better to start with criteria pertaining to the process of discovery itself, available from the outset. For instance, two minerals that seem very similar can yet be found to be completely distinct through a chemical test. In such a case, chemical methods and procedures play a decisive heuristic role for classifying minerals: "if, having formed such a classification independently of Chemistry, and compared it with the results of chemical analysis, we do find any general chemical properties which prevail in our mineralogical classes [...], it is manifest that these laws then contain important knowledge" (Whewell 1828, xxi).

A major source of inspiration for Whewell's philosophy of classification comes from the immense classificatory work carried out in natural history and chemistry. Many scholars highlighted a significant change in the means of establishing classification systems during the eighteenth and the nineteenth centuries, not only for the purposes of categorizing the numerous species of living beings newly discovered, but also an increasing number of minerals and chemical substances (cf. Diemer 1968, Klein 2003). A growing interest for classification systems based on heuristic criteria is noticeable, especially in chemistry: "Beginning in the mid-eighteenth century, chemists considered testing of the chemical properties of plant substances to be the most valuable method for their identification" (Klein 2005, 311). Such a paradigm shift is striking in Ampère's Essai d'une classification naturelle pour les corps simples (1816). Similarly, Werner (1787) and Mohs (1820) attempted to classify rocks and minerals according to the operations required for their identification and discovery (Uray 2010). But it is above all in the Linnaeus classification of natural species that Whewell recognizes the archetype of the heuristic system he covets. In this respect, he is especially sympathetic to the idea of using "artificial methods" to investigate the structure of nature, as stated in the History of Inductive Sciences:

Several of Linnaeus's classes are natural associations, kept together in violation of his own artificial rules. [...] Upon the whole, however, he rightly considered an artificial method as instrumental to the investigation of a natural one. [...] He lays down some antitheses on the subject after his manner. 'The natural orders teach us the nature of plants; the artificial orders enable us to recognise plants. The natural orders, without a key, do not constitute a Method; the Method ought to be available without a master.' (Whewell 1837, III, 266)

As it appears in this passage, Whewell endorses the Linnaeus view that a classification system is primarily a methodological tool, working as an identification key. Properties of the objects to be categorized are determined only at the end of the classificatory process, not at the beginning. That is to say that the "natural" properties of such entities are not known beforehand, and thus cannot be used as an underpinning basis for the classification. In this regard, heuristic considerations are more relevant. For instance, Whewell explains how geological strata can be classified according to the fossils they contain: "although we consider the organic fossils in each stratum as its most important characteristic, we are not prevented, by the disappearance of some fossils, or the addition of others, or by the total absence of fossils, from identifying strata in distant countries" (ibid., XIII.VIII). As fossils are not, ontologically speaking, part of the essential features of a stratum, using them as a classificatory marker hence constitute a pure "instrument of discovery" (Heathcote 1954, 311). 
In a section of the Philosophy of Inductive Sciences specifically devoted to the "classificatory sciences" (Book VIII), Whewell explains in more detail how to build a relevant classification. His ideas in this respect appear partly inspired by a Kantian line of thought. He considers that the main purpose of the classificatory process is to organize, by means of mental operations, the impressions received by the senses: "the impressions of sense are apprehended by acts of mind" (Whewell 1840, VIII.I.1). The demarcation lines between individual objects, introduced for that purpose, are not given by nature itself but rather arise from an act of the mind: "we mark this unity of each object, by drawing a line to separate the parts which we include from those which we exclude; - an Outline. This line corresponds to nothing which we see. [...] It is, as has been said by a painter of our own time, a fiction: but it is a fiction employed to mark a real act of the mind" (Whewell 1840, XIII.I). Even if such demarcation lines are drawn by human beings, they are not arbitrary, but regulated by heuristic principles. For instance, "in the Classification of Animals, we are inevitably guided by a consideration of the function of parts; that is, by an idea of purpose, and not of likeness merely" (ibid., VIII.II). More generally, a classification is not only aimed at cataloguing our theoretical space, but also plays an important heuristic role in the development of science: "the object of a scientific Classification is to enable us to enunciate scientific truths" (ibid., VIII.II.3). In other words, a classification works as a mechanism aimed at the acquisition of new scientific knowledge. By and large, the notion of "organization" conveys the idea of a complementarity between purposes and methods, according to "the Kantian definition of Organization, which I have already quoted elsewhere, 'An organized product of nature is that in which all the parts are mutually ends and means'. That this definition involves exact fundamental ideas, and is capable of being made the basis of sound knowledge, I shall hereafter endeavour to show" (Whewell 1840, IX.III.3). Such "fundamental ideas" (listed in Fig. 1) constitute a cornerstone of the Whewellian philosophy of science, and we will later explain how they serve as the basis of his classification of scientific disciplines. However, despite deriving inspiration from a claimed Kantian heritage, Whewell's "fundamental ideas" nevertheless depart significantly from the "categories" propounded by his eminent predecessor (Snyder 2006, 44). Most notably, they are not defined as concepts but rather as principles: "Ideas are not synonymous with Notions; they are Principles which give to our Notions whatever they contain of truth" (Whewell 1840, I.II.6). As a result, fundamental ideas are not epistemological categories, as in Kant's philosophical system, but heuristic principles, playing an active methodological role in the acquisition of new knowledge: "an activity according to certain Ideas is requisite in all our knowledge of external objects" (ibid., I.II.5). To put it more specifically, fundamental ideas function as an "apparatus by which bodies of facts are structured" (Fisch 1991, 158), hence their structural role in the construction of any classificatory system. They underlie the characters distinguishing the various classes of the classificatory scheme (diagnosis), alongside the diataxis, as specified here:

The construction of a Classificatory Science includes Terminology, the formation of a descriptive language;-Diataxis, the Plan of the System of Classification, called also the Systematick;-Diagnosis, the Scheme of the Characters by which the different Classes are known, called also the Characteristick. (Whewell 1840, Aphorism LXXXVII) 
An important distinction arises from this passage. On the one hand, the Diataxis (or Systematick) of a system of classification includes all natural characters underpinning the distinction of classes from one another. On the other hand, its Diagnosis (or Characteristick) specifies those marks that are heuristically relevant for identification or recognition of each class. As such, the Diagnosis constitutes "an artificial key to a natural system" (ibid., VIII.III.20). In other words, "these Artificial characters do not constitute, but indicate the genus: they are the Diagnosis, not the basis of the Diataxis" (ibid., VIII.II.8). As the Diataxis is not yet known at the beginning of the classificatory process, a classification is built according to the Diagnosis.

\section{A HeURistic Classification Of THE SCIENCES}

In light of the preceding insights, we can analyse how Whewell applies his general theory of classification to the disciplinary structure of science. Like Comte ${ }^{3}$, he considers that natural history provides a compelling model for the purpose of classifying the sciences. Such an approach was profitably used by Ampère ${ }^{4}$ in his Exposition analytique d'une classification naturelle de toutes les connaissances humaines (1834): "the classification of the sciences which M. Ampere proposes is [...] in accordance with the conditions of natural classifications, as exhibited in Botany and other sciences" (Whewell 1840, XII.XV.8). Moreover, he also strongly agrees with Ampère that a sound classification of the sciences should not be confined to a categorization of their respective objects of study, but must have "heuristic power" (Taffarelli 1980, 118). Indeed, science is primarily defined as a quest for truth, involving a methodological framework intended to lead to discovery. As a result, compartmentalizing science into subfields boils down to the systematization of its heuristic "processes". For that purpose, it is not the objects studied by each science but rather the procedures they use, that must be distributed amongst categories. In this respect the influence of Coleridge, who attempted - as stated in his Preliminary Treatise on Method (1818) - to organize the various topics of the Encylopedia Metropolitana according to their underlying methodological principles, is clearly apparent.

In order to properly understand the Whewellian approach, we must carefully distinguish: i) the objects of the classification, namely each "autonomous" science; ii) the objects studied by each science; iii) the methods of discovery implemented in each particular science; iv) the methods used to build the classification of the sciences. As explained above, the Whewellian classification of the sciences aims to organize science according to the heuristic methods implemented in each field, regardless of the objects studied by each specific science. Alongside this focus on methods within the Whewellian disciplinary system, the establishment of the classification itself relies, in turn, on a methodological approach, namely an analysis of the historical development of each science:

\footnotetext{
In his Cours de philosophie positive, Comte wrote: "Il faut déterminer maintenant le plan que nous devons suivre, c'est-à-dire, la classification rationnelle la plus convenable à établir entre les différentes sciences positives. [...] La théorie générale des classifications, établie dans ces derniers temps par les travaux philosophiques des botanistes et des zoologistes, permet d'espérer un succès réel dans un semblable travail, en nous offrant un guide certain par le véritable principe fondateur de l'art de classer, qui n'avait jamais été conçu distinctement jusqu'alors." (Comte 1830, deuxième leçon, p. 60).

4 On the influence of natural history in Ampère's classification of the sciences, see Braverman (2015).
} 
I shall take, as a chart of the country before me, by which my course is to be guided, the scheme of the sciences which I was led to form by travelling over the history of each in order. Each of the sciences of which I then narrated the progress, depends upon several of the Fundamental Ideas of which I have to speak: some of these Ideas are peculiar to one field of speculation, others are common to more. A previous enumeration of Ideas thus collected may serve both to show the course and limits of this part of our plan, and the variety of interest which it offers. (Whewell 1840, I.VIII)

The purpose of such a historical analysis is to identify the fundamental principles underlying the development of each science. Whewell "classifies particular sciences according to the kind of ideas used in their formation" (Morrison 1997, 419). He identifies a list of "fundamental ideas", each of them working as the heuristic principle of a specific science. These are displayed in the second column of Fig. 1 below, outlining the Whewellian disciplinary categorization:

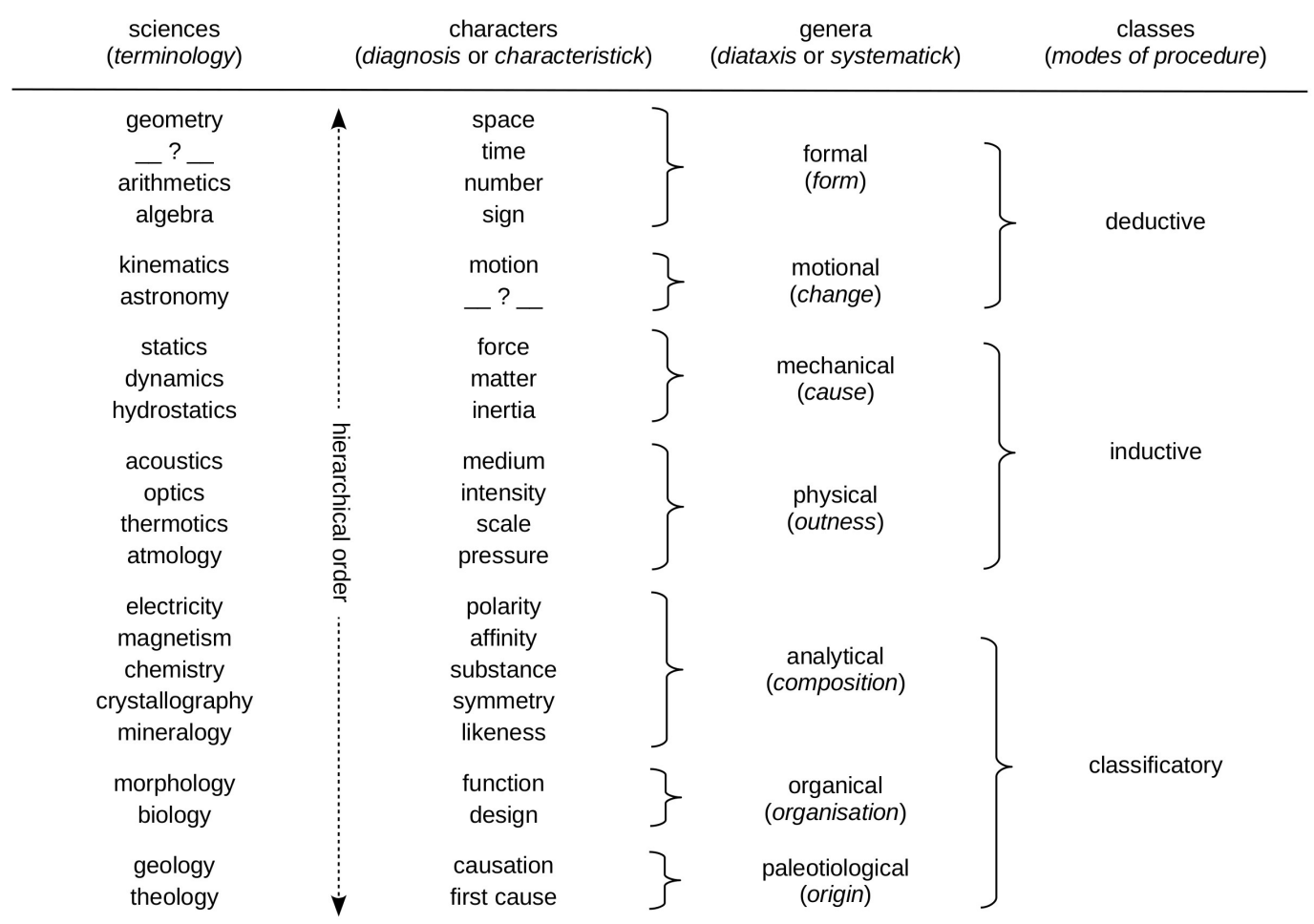

Fig. 1: Whewell's classification of the sciences

While the first two columns of this chart, though slightly simplified, are displayed almost as such in a table of the Philosophy of Inductive Sciences, it was necessary to reconstruct the latter two columns from the contents of Whewell's work. This disciplinary structure is intended by its author to constitute a fully-fledged philosophical system of the sciences: "an exposition and discussion of the Fundamental Ideas of each Science may, with great propriety, be termed the Philosophy of such Science" (Whewell 1840, I.VIII). The purpose of such a classification is not to provide a mere description of the fields already implemented in academic institutions, but to prescribe an ideal and systematic arrangement of the subfields of science based on their philosophical features. The scientific landscape is structured according to the heuristic categories defined by the fundamental ideas. Such "first principles" are not the result of the discovery process; quite the opposite, they stand at its very beginning: "first principles are not what we reason to, but what we reason from" 
(Whewell 1860, Appendix C). Such an inversion of the direction of the scientific investigation through the introduction of fundamental categories appears highly reminiscent of the "Kantian revolution". However, despite the fact that Whewell's system is undeniably marked by the thought of the German philosopher, their views nevertheless significantly diverge on many important points. In particular, the "fundamental ideas" propounded by Whewell are very different from Kant's "forms of intuition". They "do not function as conditions of experience, but as conditions for having knowledge" (Synder 2006, 44). In other words, they are not the categories of the human mind, but the first elements of our heuristic toolkit. Thus, a departure from the epistemological orientation of the Kantian fundamental categories is unavoidable, and it is clearly the reason why he "did not follow Kant in distinguishing between the a priori components of knowledge provided by intuition, the Understanding, and the faculty of Reason" (Snyder 2006, 44). Another interesting difference is that "Whewell did not attempt to give an exhaustive list of these Fundamental Ideas" (Snyder 2006, 44). Indeed, as it appears in Fig. 1, his classification table includes several empty spaces, allowing room for new heuristic tools that may lead, in the future, to the advent of new sciences.

In most systems of the sciences, and especially in the Baconian classification, the categorization of the various classes of scientific disciplines is structured around what Whewell calls "fundamental antitheses": various opposing pairs of concepts, such as "ideas and sensations", "theories and facts", or "matter and form". From the implementation of such conceptual oppositions comes, for instance, the traditional distinction between "rational sciences", like mathematics and logic, and "empirical sciences", like chemistry and physics. However, Whewell argues that the conceptual opposition between the terms of such antitheses is merely an illusion. It is impossible to separate the empirical content of science from the intellectual reasonings driving our investigations of the world. Such recognition of the "theory-ladenness of our data" (Buchdahl 1971, 350) has a deep influence on his classification of the sciences: "despite the supposed separation of the elements of knowledge that results from its antithetical nature, the antithesis itself is in some sense incapable of fulfilling that goal" (Morrison 1997, 420). As a consequence, Whewell must base his disciplinary system on very different foundations than the epistemological underpinnings of the Baconian system. As we will see, he overrides the limitations of the antithesis in trading such an epistemological system for a heuristic classification instead, grouping the different sciences according to their methodological principles, derived from fundamental ideas:

The branches of knowledge thus grouped in one class involve common Fundamental Ideas, from which their principles are derived in a mode analogous, at least in a certain degree, to the mode in which the principles of the mechanical sciences are derived from the fundamental ideas of causation and reaction. (Whewell 1840, III.X.9)

Such fundamental ideas are collected by Whewell through a historical analysis of the methods implemented in each of the sciences (it is the main goal of the project he carried out in the History of the Inductive Sciences). Such an approach provides him with the diagnosis of the heuristic components of science: fundamental ideas, given in the second column in Fig. 1, are the characters enabling the recognition of natural genera of sciences. Then, each family is known through an analysis of the processes carried out to infer knowledge from the fundamental ideas. A list of such genera of 
sciences is drawn up in the third column of our chart. The first genus, formal sciences, includes mathematical sciences, and proceeds from the notion of form: "Space, time, and number, may be conceived as forms by which the knowledge derived from our sensations is moulded. [...] The sciences which have these ideas for their subject may be termed Formal Sciences" (ibid., II.I.5). Motional sciences constitute a second genus whose principle is change. This group of sciences relies on the principles implemented in the first one: "the perception of motion, that is, change of place, presupposes the conception of time" (ibid., II.VII.4). Next, the group of mechanical sciences proceeds from the notion of cause: "force, in its most general sense, is the cause of motion, or of tendency to motion; and in order to discover the principles on which the Mechanical sciences truly rest, we must examine the nature and origin of our knowledge of Causes" (ibid., III.I). The fourth genus, physical sciences, is based on the notion of outness or externality: "In reasoning concerning the secondary qualities of bodies, we are led to assume the bodies to be external to us. [...] It may be remarked that this apprehension of objects as external to us, although it assumes the idea of space, is far from being implied in the idea of space" (ibid., IV.I.2). This notion of externality gives rise to the need for analytical sciences, focused on the composition of material bodies: "in other parts of human knowledge, we shall find that there are certain ideas, deeply seated in the mind, though shaped and unfolded by external observation, [...] which impel man to such a knowledge of the composition of bodies" (ibid., IV.I.2). The next genus, organical sciences, deals with the notion of organization: "In the organical sciences, the assumption of design and purpose in every part of every whole, that is, the pervading idea of Final Cause, is the basis of sound reasoning and the source of true doctrine" (ibid., IX.VI.12). Last but not least, palaetiological sciences are concerned with the notion of origin: "In all Palaetiological Sciences, in all attempts to trace back the history and discover the origin of the present state of things, the portion of the science which must first be formed is that which classifies the phenomena" (ibid., X.II.7).

As displayed in the last column in Fig. 1, these genera of sciences are in turn grouped at a higher classificatory level, according to their "modes of procedure", and distributed into three main classes of sciences: deductive, inductive and classificatory, respectively. The criteria used for building these groups are the processes involved in the discovery of truth in each class of sciences. A first heuristic mode, deduction, is implemented in Deductive Sciences (also called Pure Sciences): "these sciences have no principles besides definitions and axioms, and no process of proof but deduction [...] The principal sciences of this class are Geometry, Theoretical Arithmetic, and Algebra" (ibid., II.I.1). The second mode of discovery — and that most analysed by Whewell—is the induction process, underpinning the class of Inductive Sciences: "in all these Sciences it is familiarly understood and assumed, that their doctrines are obtained by a common process of collecting general truths from particular observed facts, which process is termed Induction" (ibid., I.I). Physical and mechanical sciences proceed in such manner. The third heuristic modality is the classification process, leading to the aforementioned group of the Classificatory Sciences, including biology and mineralogy: "the examples of the successful application of this method [of grouping objects into classes] are to be found in the Classificatory Sciences through their whole extent; as, for example, in framing the Genera of plants and animals" (ibid., XIII.VIII.12). 
However, such a partitioning of science into separate fields should not jeopardize its essential wholeness. As highlighted by Yeo (1993, chap. 9), Whewell attempts to conceive of a disciplinary system preserving the unity of science, a conceptual effort explicitly evidenced in his discussion of Mary Somerville's major work, On the Connection of the Physical Sciences (1834). In a eulogistic article specifically devoted to this book, he supports her idea that separate branches of science must be unified through overarching methodological principles:

The inconveniences of this division of the soil of science into infinitely small allotments have been often felt and complained of. [...] To remove the evil in another way is one object of Mrs. Somerville's book. If we apprehend her purpose rightly, this is to be done by showing how detached branches have, in the history of science, united by the discovery of general principles. (Whewell 1834, 60)

Such an attempt to "bind the disparate branches of natural philosophy firmly together [with a] methodological glue" (Shortland 1990, 31) is achieved by Whewell through the implementation of a hierarchical order of the principles implemented in the various sciences: "It is to be observed also that in our classification, each Science may involve, not only the Ideas or Conceptions which are placed opposite to it in the list, but also all which precede it" (ibid., XI.IX.2). A series of heuristic steps are achieved from formal to palaetiological sciences. The different genera and classes of sciences are subordinated to each other: "the genealogical tree of each great portion of science, thus formed, will contain all the leading truths of the science arranged in their due co-ordination and subordination" (ibid., XI.VI.2). Disciplinary groups are ordered in a progression; they correspond to "different stages of generalisation" in a gradation towards "the highest step of the process of discovery, to which all others are subordinate and preparatory" (ibid., XI.VI.1). As a result, it is no longer required to compartmentalize the structure of science by means of impervious disciplinary borders underpinned by questionable antinomies: each "class is steadily fixed, though not precisely limited; it is given, though not circumscribed; it is determined, not by a boundary line without, but by a central point within" (ibid. VIII.II.10). Major differences remain between deductive, inductive and classificatory sciences; however, their guiding principles become complementary, a feature that affords science its unity. The processes enabling the advancement of higher sciences can also be involved in lower sciences (for instance, the use of mathematical methods in physics). According to Whewell, the Aristotelian disciplinary system failed to implement such a subordination principle: “Aristotle's classification [...] cannot be said to anticipate any modern system, because the different grades of classification are not made subordinate to one another as a system of classification requires" (Whewell 1860, V.7). In this respect, the Whewellian hierarchical system rather echoes the "hiérarchie des sciences positives" propounded by Comte (Pont 2007, 476). However, Whewell is very critical, overall, of the Comtian disciplinary system, which fails to account for the heuristic principles enabling the development of science: "As M. Comte refuses to admit into his philosophy the fundamental idea of Cause, he of course excludes most of the other ideas, which are, as we endeavoured to show, the foundations of science" (Whewell 1840, XII.XVI). This rejection results in a "failure of this attempt of M. Comte at distinguishing these provinces of science by their objects" (Whewell 1860, XXI.7). 
The Whewellian idea of basing the hierarchical classification of the sciences on their historical development exerted a significant influence on the philosophy of Herbert Spencer. In The Genesis of Science, he refers to Whewell in alleging that the various sciences must be ordered in accordance with the evolution of their degree of generality: "Commencing with the complex and the special, mankind have progressed step by step to a knowledge of greater simplicity and wider generality. So much evidence is there of this as to have drawn from Whewell, in his History of the Inductive Sciences, the general remark that 'the reader has already seen repeatedly in the course of this history, complex and derivative principles presenting themselves to men's minds before simple and elementary ones"' (Spencer 1854, 179). Such an idea fits perfectly into the scheme of Spencer's overall project of developing a "genealogy of the sciences consistent with the general spirit of the theory of evolution" (Tort 1987, 24). Sciences are ordered according to their "degree of generality", in a hierarchy enabling the possibility of a smooth transition from one science to another (Tort 1987, 30 ). Whilst his disciplinary classification system appears to be more grounded in ontological categorizations than the heuristic system propounded by Whewell, he nevertheless attempted to capture the principles underlying each science (Spencer 1870) — an approach echoing, to some extent, the quest for "fundamental ideas": "Recognizing the influence of Whewell, Herschel and Mill on Spencer's thinking is the key to understanding the methodological views set out in First Principles" (Haines 1992, 168).

It appears that the Whewellian disciplinary system also exerted an important influence on the arrangement of the sciences put forward by Charles Saunders Peirce ${ }^{5}$. His Outline Classification of the Sciences (1903) establishes a division of theoretical disciplines into two main classes: the first group, entitled "science of discovery" (or "heuretic sciences"), includes all fields properly regarded as scientific ${ }^{6}$, while the second group, "science of review", merely aims at organizing the results of the former class. Such a system perfectly fits into the scheme of a heuristic disciplinary paradigm, defining the sciences through the specific methods they use: "Peirce understood the term 'science' in broad terms as that which illustrated a systematic, institutionalised method of organising any body of human knowledge. It is not knowledge or opinions as such, but a method of reaching them" (Pietarinen 2006, 12). In addition, Peirce also propounded a hierarchy of the sciences: "Peirce's architectonic clearly delineates a procedure for inquiry, delimits the aim of each science and states its authority over or subjection to the other sciences." (Atkins 2006, 497). Furthermore, he praised Whewell for having drawn his classification from an analysis of the historical development of each of the sciences: "My own historical studies [...] confirmed the views of Whewell, the only man of philosophical power conjoined with scientific training who had made a comprehensive survey of the whole course of science, that progress in science depends upon the observation of the right facts by minds furnished with appropriate ideas" (Peirce, CP 6.604).

Such an influence has been highlighted by several historians: "Peirce wrote approvingly of Whewell's work" (Kent 1987, 220); "Peirce was to all appearances quite strongly influenced but did not explain how his work grew out of Whewell's" (Wettersten 1994, 735).

6 As noted by Kent, "the word 'science', [understood] in its restricted sense, can only apply to the heuretic sciences, the sciences of discovery" (Kent 1987, 82). 


\section{Conclusion}

To summarize, it follows from our analysis that Whewell's quest for a heuristic categorization of the sciences actually heralded an important overhaul of the disciplinary paradigm, occurring by the middle of the nineteenth century. During this pivotal period, the Baconian influence eroded, and the epistemological model of the "tree of knowledge" was gradually replaced by more methodological considerations for establishing the delimitations between the sciences. In this respect, the innovative disciplinary system propounded by Whewell - alongside those of Ampère, Coleridge, and Comte, and through the strong influence it exerted on Peirce and Spencer-significantly contributed to deeply reshaping the disciplinary landscape.

Moreover, we hope to have highlighted the central role of the Whewellian classification of the sciences within his whole philosophical project. It appears that he primarily attempted to achieve the diagnosis of science through an analysis of its heuristic components. This is the main purpose of his large-scale historical overview of the development of science. In this work, aimed at capturing the fundamental processes enabling the advancement of the various scientific areas, he collects the guiding methodological principles implemented in each field. Following this, the Whewellian disciplinary scheme achieves an integration of these methodological components into a coherent system. As diagrammatically illustrated through the "inductive tables" included in the Philosophy of Inductive Sciences, the process of discovery involves a series of heuristic steps ordered in a specific manner. It means that the methods distributed across scientific fields are complementary: each discipline provides science with a heuristic element indispensable to its progress. As a result, there is no way to compartmentalize science into isolated disciplines separated from one another by impervious borders. As explained above, the idea of the fundamental unity of science pervades the Whewellian philosophy (Yeo 1993, 231). In hierarchizing the methods of discovery, the disciplinary system put forward by Whewell enables one to distinguish the different subfields of science without sacrificing its unity. Such an approach is of topical interest and deserves reassessment in the context of the challenging demands in our time of both specialization and interdisciplinarity.

\section{ACKNOWLEDGMents}

The research carried out in this paper was supported by the Swiss National Science Foundation, through a postdoctoral fellowship at the University of Oxford (grant P2GEP1-155682). 


\section{REFERENCES}

Ampère, A.-M. (1816). "Essai d'une classification naturelle pour les corps simples." In Annales de chimie et de physique, 295-308, 373-94. Paris: Masson.

- (1834). Essai sur la philosophie des sciences: ou, Exposition analytique d'une classification naturelle de toutes les connaissances humaines. Paris: Bachelier.

Atkins, R. (2006). "Restructuring the Sciences: Peirce's Categories and His Classifications of the Sciences." Transactions of the C.S.Pierce Society 42 (4): 483-500.

Bacon, F. (1612). “A Description of the Intellectual Globe." In The Philosophical Works of Francis Bacon, edited by J. M. Robertson, 670-701. London: Routledge.

Braverman, C. (2015). "La classification scientifique chez Ampère : entre Bacon et les naturalistes." Revue philosophique de la France et de l'étranger 140 (3): 307-24.

Buchdahl, G. (1971). "Inductivist Versus Deductivist Approaches in the Philosophy of Science as Illustrated by Some Controversies Between Whewell and Mill." The Monist 55 (3): 343-67.

Cantor, G. N. (1991). "Between Rationalism and Romanticism: Whewell's Historiography of the Inductive Sciences." In William Whewell, a Composite Portrait, by M. Fisch \& S. Schaffer, 67-86. Oxford: Clarendon Press.

Cobb, A. D. (2011). "History and Scientific Practice in the Construction of an Adequate Philosophy of Science: Revisiting a Whewell/Mill Debate." Studies in History and Philosophy of Science Part A 42 (1): 85-93.

Coleridge, S. T. (1818). General Introduction to the Encyclopaedia Metropolitana; Or, Preliminary Treatise on Method. Constable \& Company, 1934.

Comte, A. (1830). Cours de philosophie positive. Paris: Bachelier.

Diemer, A. (ed.). (1968). System Und Klassifikation in Wissenschaft Und Dokumentation: Vorträge Und Diskussionen Im April 1967 in Düsseldorf. Meisenheim am Glan: A. Hain.

Fisch, M. (1985). "Necessary and Contingent Truth in William Whewell's Antithetical Theory of Knowledge." Studies in History and Philosophy of Science Part A 16 (4): 275-314.

. (1991). William Whewell, Philosopher of Science. Oxford [UK] ; New York: Clarendon Press ; Oxford University Press.

Fisch, M. \& Schaffer, S. (eds.). (1991). William Whewell, a Composite Portrait. Oxford: Clarendon Press.

Flint, R. (1904). Philosophy as Scientia Scientiarum : And, A History of Classifications of the Sciences. New York: Arno Press, 1975.

Heathcote, A. W. (1954). "William Whewell's Philosophy of Science." The British Journal for the Philosophy of Science 4 (16): 302-14. 
Kent, B. (1987). Charles S. Peirce: Logic and the Classification of the Sciences. McGill-Queen's University Press.

Klein, U. (ed.). (2003). Spaces of Classification. Max-Planck Institute for the History of Science, Preprint $\mathrm{n}^{\circ} 240$.

. (2005). "Shifting Ontologies, Changing Classifications: Plant Materials from 1700 to 1830." Studies in History and Philosophy of Science Part A 36 (2): 261-329.

Mohs, F. (1820). The Characters of the Classes, Orders, Genera, and Species: Or, The Characteristic of the Natural History System of Mineralogy. Edinburgh: W. \& C. Tait.

Morrison, M. (1997). "Whewell on the Ultimate Problem of Philosophy." Studies in History and Philosophy of Science Part A 28 (3): 417-37.

Peirce, C. S. (1903). “An Outline Classification of the Sciences." In The Essential Peirce: Selected Philosophical Writings (1893-1913), 258-62. Indiana University Press, 1998.

(1974). Collected Papers of Charles Sanders Peirce. Harvard University Press.

Pietarinen, A.-V. (2006). "Interdisciplinarity and Peirce's Classification of the Sciences: A Centennial Reassessment." Perspectives on Science 14 (2): 127-52.

Pont, J.-C. (2007). "Auguste Comte et William Whewell : Euvres Contemporaines." Revue Philosophique de La France et de l'Étranger 197 (4): 471-91.

Shortland, M. (1990). "On the Connexion of the Physical Sciences. Classification and Organization in Early Nineteenth-Century Science.” Historia Scientiarum 41: 17-36.

Snyder, L. J. (1999). "Renovating the Novum Organum: Bacon, Whewell and Induction." Studies in History and Philosophy of Science 30 (4): 531-57.

- (2006). Reforming Philosophy: A Victorian Debate on Science and Society. University of Chicago Press.

Somerville, M. (1834). On the Connection of the Physical Sciences. London: John Murray.

Spencer, H. (1854). The Genesis of Science and the Factors of Organic Evolution. Humboldt Publishing Company.

(1870). First Principles of a New System of Philosophy. New York: D. Appleton.

Taffarelli, J.-L. (1980). Les Systèmes de Classification Des Ouvrages Encyclopédiques. E.N.S.B.

Tort, P. (1987). "Spencer et le système des sciences." In Autobiographie: naissance de l'évolutionnisme libéral, by H. Spencer. Paris: Presses Universitaires de France.

Totok, W. (1980). "Wissensordnung und Ordnungswissen zwischen Renaissance und Aufklärung." Studien zur Klassification 9: 197-215.

Uray, J. (2010). "Chemische Theorie und mineralogische Klassifikationssysteme von der chemischen Revolution bis zur Mitte des 19. Jahrhunderts." In Die Anfänge geologischer Forschung in Österreich, by B. Hubmann, E. Schübl, \& J. Seidl. Graz: Leykam. 
Werner, A. G. (1787). Kurze Klassifikation und Beschreibung der verschiedenen Gebirgsarten. Dresden: Walther.

Wettersten, J. (1994). "William Whewell: Problems of Induction vs. Problems of Rationality." The British Journal for the Philosophy of Science 45 (2): 716-42.

- (2005). Whewell's Critics: Have They Prevented Him from Doing Good? Amsterdam: Rodopi.

Whewell, W. (1828). An Essay on Mineralogical Classification and Nomenclature: With Tables of the Orders and Species of Minerals. Cambridge: J. Smith.

—. (1834). "Mrs. Somerville on the Connexion of the Sciences." Quarterly Review 51: 54-68.

—. (1837). History of the Inductive Sciences. London: J. W. Parker, 1857.

- (1840). The Philosophy of the Inductive Sciences: Founded upon Their History. 2 vols. London: J. W. Parker, 1847.

—. (1860). On the Philosophy of Discovery. London: J. W. Parker.

- (1876). William Whewell - An Account of His Writings with Selections from His Literary and Scientific Correspondence. Ed. I. Todhunter. London: Macmillan.

Wilson, D. B. (2011). "William Whewell, Galileo, and Reconceptualizing the History of Science and Religion." Notes and Records of the Royal Society of London 65 (4): 343-58.

Yeo, R. (1979). "William Whewell, Natural Theology and the Philosophy of Science in Mid Nineteenth Century Britain.” Annals of Science 36 (5): 493-516.

. (1993). Defining Science: William Whewell, Natural Knowledge and Public Debate in Early Victorian Britain. Cambridge: Cambridge University Press. 
sciences

characters

genera

classes

(terminology)

(diagnosis or characteristick) (diataxis or systematick)

(modes of procedure)

geometry
arithmetics
algebra
kinematics
astronomy
statics
dynamics
hydrostatics
acoustics
optics
thermotics
atmology
electricity
magnetism
chemistry
crystallography
mineralogy
morphology
biology
geology
theology

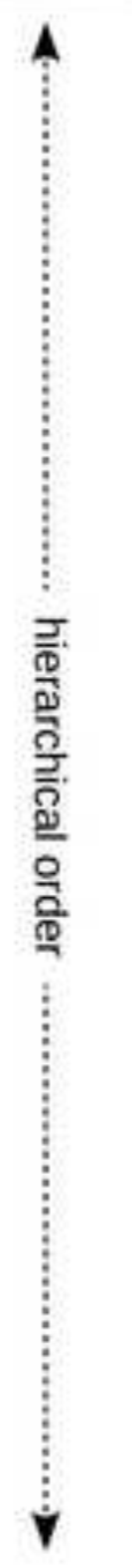

$\left.\begin{array}{c}\left.\begin{array}{c}\text { space } \\ \text { time } \\ \text { number } \\ \text { sign } \\ \text { motion } \\ \text { ? }\end{array}\right\} \\ \text { force } \\ \text { matter } \\ \text { inertia } \\ \text { medium } \\ \text { intensity } \\ \text { scale } \\ \text { pressure } \\ \text { polarity } \\ \text { affinity } \\ \text { substance } \\ \text { symmetry } \\ \text { likeness } \\ \text { function } \\ \text { design } \\ \text { causation } \\ \text { first cause }\end{array}\right\}$

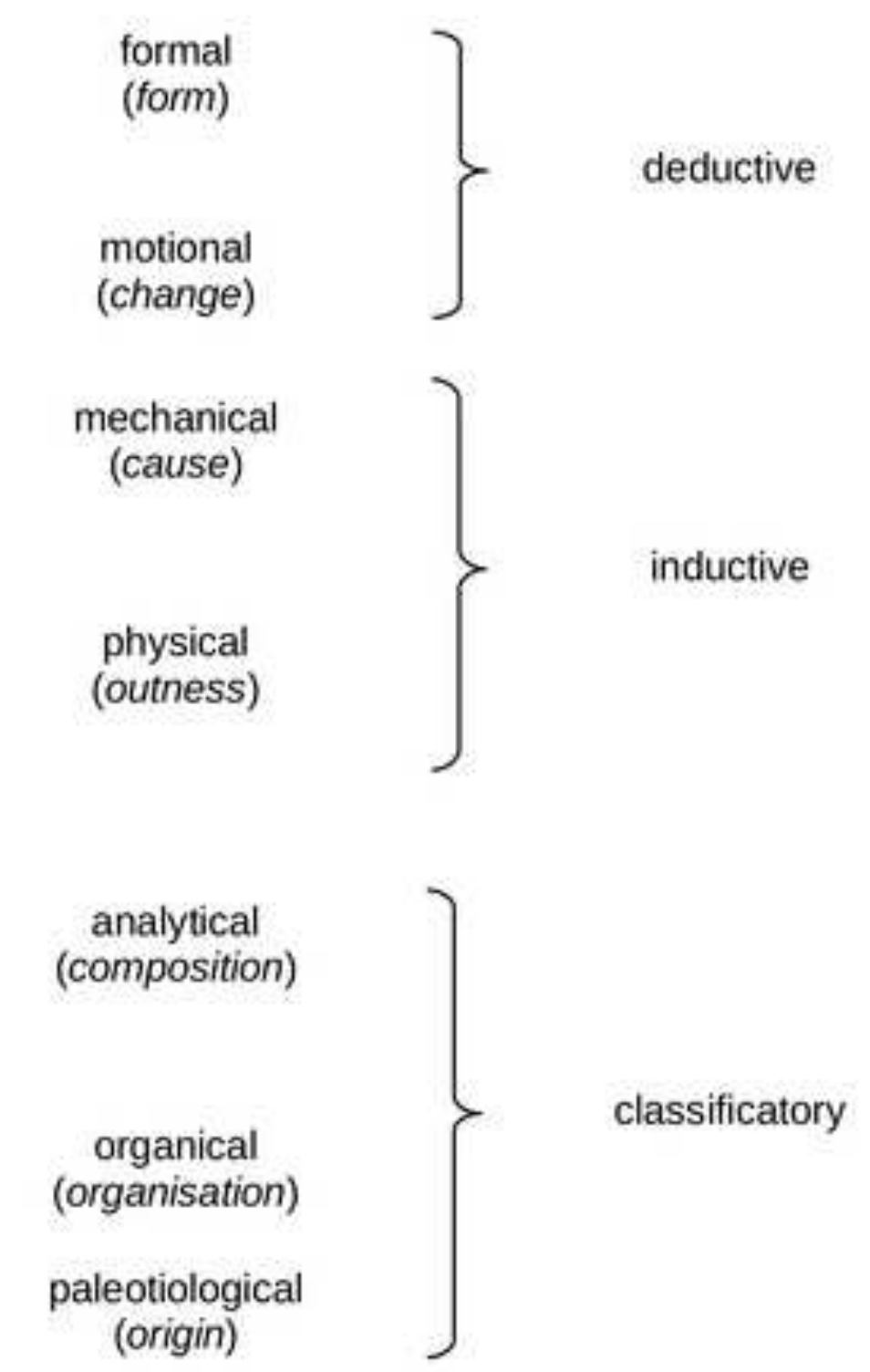

